This is a postprint version of the following published document:

Artero-Guerrero, J.A.; Pernas-Sánchez, J.; López-Puente, J.; Varas, D. (2015). Experimental study of the impactor mass effect on the low velocity impact of carbon/epoxy woven laminates. Composite Structures, 133, pp . 774- 781.

DOI: $\underline{10.1016 / j . c o m p s t r u c t .2015 .08 .027}$

Proyecto: DPI2013-41094-R

(C) Elsevier 2015

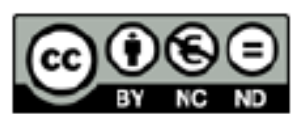

This work is licensed under a Creative Commons Attribution-NonCommercialNoDerivatives 4.0 International License. 


\title{
Experimental study of the impactor mass effect on the low velocity impact of carbon/epoxy woven laminates
}

\author{
J.A. Artero-Guerrero, J. Pernas-Sánchez, J. López-Puente, D. Varas
}

Department of Continuum Mechanics and Structural Analysis, University Carlos III of Madrid, Avda. de la Universidad, 30, 28911 Leganés, Madrid, Spain

\begin{abstract}
A B S T R A C T
In this work, the analysis of the impactor mass effect on the behaviour of carbon/epoxy woven laminates under low velocity impact is carried out. To this end experimental test were performed by means of a drop weigh tower in a range of energies varying from 10 to $110 \mathrm{~J}$, and using three different impactor masses. Two different laminate thicknesses were considered in order to take into account its possible influence. An analysis of the impact tests is performed using the Composite Structure Impact Performance Assessment Program, in order to observe the influence of impactor mass. Once impacted, the laminates were inspected by means of a C Scan (to quantify the delamination extension) and a phased array ultrasonic system (to analyse the failure through the thickness); this non destructive anal ysis will determine the influence of the impactor mass on the laminate failure.
\end{abstract}

Keywords: Woven carbon/epoxy, Drop weight tower, Low velocity, Impactor mass

\section{Introduction}

The use of composite laminates by the aeronautic industry has increased significantly in the last years. One example of this increase is the use of these materials in the recent developments performed by the two largest civil aircraft company manufactures, where the use of composite laminates in the structure has achieved $50 \%$ in terms of weight. In addition to this field, recently the auto motive industry has started to use this type of materials in the vehicle structures, in order to reduce the energy consumption in the new generation of electric cars.

It is well known that composite laminates, in particular those made with carbon fibres and epoxy matrix, present exceptional specific mechanical properties. One of the main drawbacks of these materials is the low resistance against impact when happens per pendicularly to the laminate plane. Impacts on composite lami nates could generate internal damage (matrix cracking, delamination...etc.) that could not be observed externally, and which could cause a very important diminution of the mechanical properties.

When analysing the impact on composites laminates, a differ entiation between high and low velocity impact is usually done. High velocity impacts are those related to small masses (of an order of magnitude of grams) whereas low velocity impacts are associated to larger masses (of an order of magnitude of

\footnotetext{
* Corresponding author. Fax: +34 916249973.

E-mail address: dvaras@ing.uc3m.es (D. Varas).
}

kilograms). The first type of impacts have been studied by many authors starting from Cantwell and Morton [1,2] from an experi mental [3 7], numerical [8 10] and analytical [11,12] point of view; also the authors of this work have published several articles analysing the behaviour of composites impacted by projectiles with different geometries and incident angles, always at high velocity $[6,10]$.

Low velocity impacts on composite laminates may occur in many different situations. Aircraft structures in service can be sub jected to this kind of impacts during maintenance operations or from ground support equipment. In the case of ground vehicles, automotive structures can be impacted at low velocity by different objects (another vehicle or small stones) causing different types of damages. The first works that investigate the low velocity impact on composite laminates appear in the 80s; one example is the work of Caprino et al. [13], in which the authors stated that the main governor parameter is the impact energy. In the following years Cantwell et al. $[1,2,14]$ presented different works in which low velocity impact tests were performed using a drop weight tower apparatus, to analyse the influence of several parameters on the damage extension of carbon/epoxy laminates.

In the following decade, most of the works in which the behaviour of composite laminates under low velocity impact was studied, focused its attention in the residual strength after impact [15 19]. For the aeronautic industry this subject is of great impor tance, since damage tolerance is a key factor on their design requirements. Apart from those works it is important to mention the work of Pavier and Clarke [20], which analysed the complex 
damage patterns that appear at low velocity impact for both delamination and matrix cracking. It has to be mentioned the work of Jackson and Poe [21] where it has been studied the influence of laminate thickness, support span and boundary conditions in the contact force generated. And finally another interesting study of those years is the article of Kim et al. [22], which performed an analysis of the effect of the laminate architecture on its behaviour under low velocity impact.

From the 2000 onwards, most of the experimental works related to the low velocity impact on composite laminates, were focused in obtaining data to validate numerical methodologies to predict its behaviour. Johnson et al. [23] proposed a continuum damage mechanics numerical modelisation of composite lami nates, including delamination and in ply failure; the comparison with experimental tests showed a good correlation. In the follow ing years many other works appeared with different approaches [24 29]; those works focused its attention in obtaining good corre lations with the delaminated area measured in experimental tests. In addition of these articles, is worth to mention two more works $[30,31]$ which studied experimentally different geometry parame ters, impactor and laminate size, impactor shape and laminate boundary conditions to analyse its influence in the laminate behaviour.

Most of the previous experimental studies on this field are based on constant mass testing procedures without taking into account how this impact energy is achieved (mass and velocity combination). Different impact velocities lead into different strain rates, and some authors have established that strain rate effects may play a role in the behaviour of laminates subjected to low velocity impact [32]. Woven and tape laminates have different strain rate sensitivity [33], and hence it is important to distinguish them.

Several works have studied the effect of impactor mass on low velocity impacts on tape laminates, reaching to similar conclu sions. Ambur et al. [34] impacted four different masses (ranging from 1.1 to $9 \mathrm{~kg}$ ) against 48 plies laminates; in the range studied (from 10 to $33 \mathrm{~J}$ ) no clear influence was found regarding the impac tor mass. Feraboli et al. [35] studied different parameters in low velocity impacts including the impactor mass; one of the main conclusions was that equienergetic impacts doubling the impactor mass do not produce any effect on damage and residual stiffness. Finally in the article of Bucinell et al. [36], mass ratio between the heaviest and the lightest was increased up to 5, and even with this large variation of impactor mass, the peak force measured by the striker was found to be only a function of the impact energy. With those results it could be concluded that tape laminates do not show impactor mass influence for the same impact energy.

The strain rate effect was found to be not negligible for woven laminates [33,37]. It is possible to find some works [37 40] in which the strain rate sensitivity has been studied, obtaining sensi ble variations in the strength properties. Regarding the behaviour of this architecture under low velocity impacts, different authors have obtained different conclusions regarding the influence of impactor mass. Robinson and Davies [41] studied the influence of impactor mass in $2 \mathrm{~mm}$ carbon/epoxy woven laminates; in this case three different masses $(1.15,1.59$ and $2.04 \mathrm{~kg})$ have been used for the analysis, concluding that, in the range of energies studied (up to 12 $\mathrm{J}$ ) impact damage was function only on impact energy. More recently, Zabala et al. [32], analysed the damage generated by equienergetic impacts using five different masses (from 2 to $9 \mathrm{~kg}$ ) in $2.3 \mathrm{~mm}$ thickness CFRP woven laminates. In this case, they have focused in the energy range in which only delamination is induced (from 1.5 to $9 \mathrm{~J}$ ) arguing that only matrix dominant damages are rate sensitive. They have found that lighter impacts generates higher delaminated area, because of the decrease of interlaminar fracture toughness as the impact velocity (and therefore strain rate) increases. Later, the same researchers have found similar conclusions in double cantilever beam test per formed at different rates [42]. It is possible to state that in the case of woven carbon/epoxy laminates, there is no clear consensus about the influence of the impactor mass.

In an attempt to clarify the influence of impactor mass in woven laminates, this work presents the analysis of low velocity impact test using three different impactor masses in a wider energy range than previous works, where both delamination and fibre failure are presented. The influence of impactor mass is also studied in two different laminate thicknesses. In order to perform the analysis of the influence of impactor mass, a systematic study of the impact has been carried out using the Composite Structure Impact Performance Assessment Program (CSIPAP) proposed by Feraboli and Kedward [35]. Since it is expected that the impactor mass effect on the failure mechanism for equienergetic impacts could be small, a detailed damage inspection has been performed in the current work using conventional $\mathrm{C}$ Scan and a detailed $\mathrm{C}$ Scan using a phased array ultrasonic system to obtain the in plane and through thickness delamination shape.

\section{Material and experimental methods}

Low velocity impact tests on carbon/epoxy woven laminates were performed by means of an INSTRON CEAST Fractovis 6875 drop weight tower. The composite specimens were hit orthogo nally with a striker bar which is free fall accelerated through a guide. At the end of the bar a $20 \mathrm{~mm}$ diameter hemispherical nose is placed; the striker bar is instrumented in order to register the impact force. The apparatus allows the possibility of performing impacts at different energies, varying both the impact velocity (adjusting the initial heigh) and the mass (attaching masses to the striker). After the impact, an anti rebound system held the stri ker to avoid multi hits on the specimen. Since the objective of this work is to analyse the influence of impactor mass, different equienergetic impacts were performed using three impactor masses: $3.8,7.8$ and $15.8 \mathrm{~kg}$. The range of the impact energy was varied from 10 to $110 \mathrm{~J}$, while the initial velocity was varied from $1.12 \mathrm{~m} / \mathrm{s}$ in the case of lowest energy with the highest weight to $6.9 \mathrm{~m} / \mathrm{s}$ in the case with the lowest weight at the highest energy. Fig. 2 summarises the experimental tests performed with each impactor mass, detailing the impact velocity and the kinetic energy.

Impact test were record by means of a high speed camera (Photron SA Z $2100 \mathrm{~K}$ ), configured at $20000 \mathrm{fps}$ and with a resolu tion of $1024 \times 1024$ pixels. Using a mirror placed under the speci men with an inclination of $45^{\circ}$, it was possible to visualise at the same time the impactor movement and the back face of the lami nate, allowing to observe the initiation of the fibre failure and the propagation of it. A sketch of the experimental set up used to record the impact process can be observed in Fig. 1. It also includes a frame obtained by the high speed camera; the central region of the back face of the laminate has been painted in white allowing a better identification of the fibre failure.

The composite laminates chosen for these experimental tests were woven carbon/epoxy laminates manufactured using auto clave methods in the Instituto Nacional de Tecnicas Aeroespaciales. This architecture is widely used in aeronautic structures, mainly when they are subjected to in plane shear stres ses. A completely description of the mechanical properties could be found in previous works of the same authors of this work $[8,10]$. The specimens were $120 \times 120 \mathrm{~mm}^{2}$ square plates made of AS4 fibre and 8552 epoxy woven laminates, denominated commer cially AGP193 PW by its manufacturer, Hexcel Composites. Two different thicknesses were used, 4.4 and $6.6 \mathrm{~mm}$, which correspond 

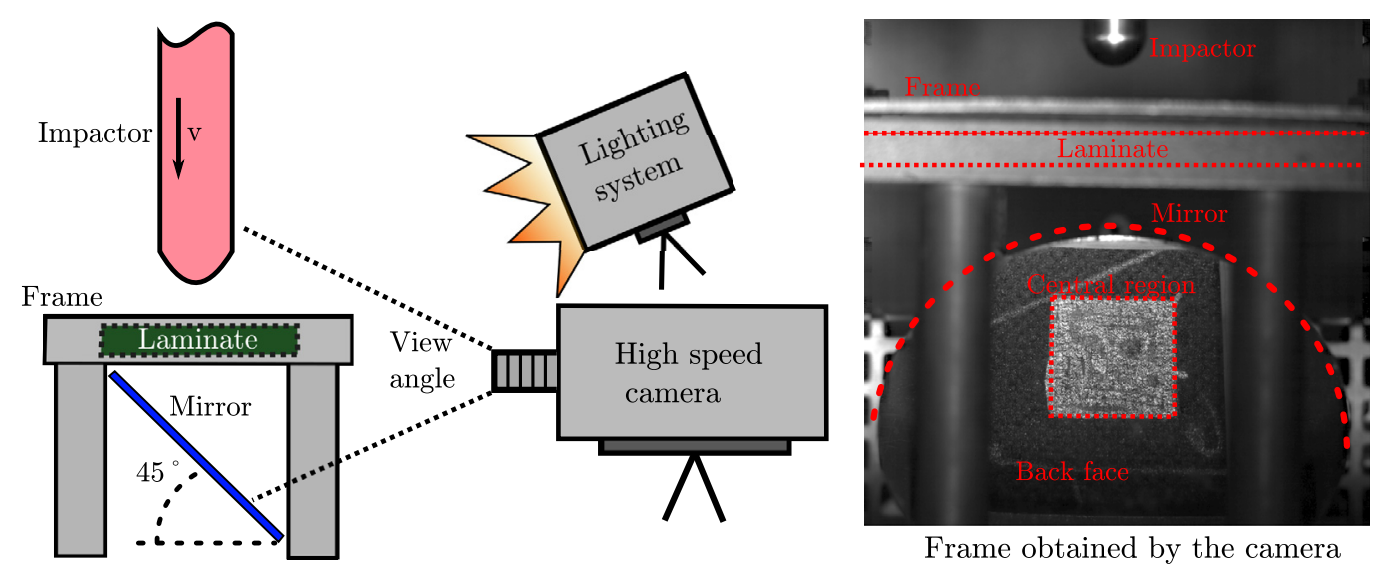

Fig. 1. Sketch of the experimental set-up used for the recording of the impact process, and a frame obtained with it.

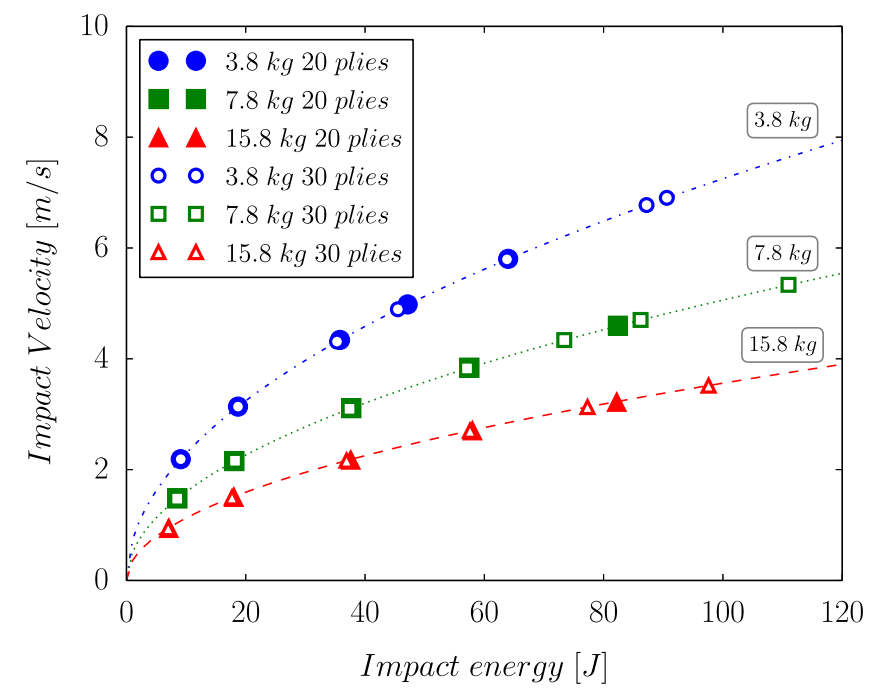

Fig. 2. Summary of impact test performed in this study.

to 20 and 30 plies. The specimens were placed on a steel support and clamped along their outer border, leaving a free span of $80 \times 80 \mathrm{~mm}^{2}$. The ratio between the impactor diameter and the free span assures that the damage of the composite does not reach the clamped zone.

In order to analyse the influence of the impactor mass and com pletely characterise the impact performance of composite plates under low velocity impacts, the Composite Structure Impact Performance Assessment Program (CSIPAP) proposed by Feraboli and Kedward [35] has been used. This methodology stablish that the peak force, energy, coefficient of restitution (COR), contact duration and residual stiffness plots constitute the key information to assets a completely analysis.

Using the force history obtained from the instrumented striker it is possible to calculate the acceleration (which is proportional to the force, scaled by the falling mass), the velocity and the displace ment (by simple integration) and finally the energy time history (combining force and displacement); this calculations are possible if it is assumed that there is full contact between striker and spec imen throughout the test [32]. The procedure to calculate the COR and the residual stiffness will be explained later.

Once impacted, composite laminates were subjected to an non destructive damage analysis. Firstly, an ultrasonic inspection with a $5 \mathrm{MHz}$ transducer (C Scan technique) is conducted in order to determine the shape and extension of the delaminated area. Secondly an Olympus Omniscan SX phased array ultrasonic system is used to obtain a detailed C Scan and a B Scan with the position of the delamination through the thickness of the laminate.

\section{Impact tests analysis}

\subsection{Drop weight tower}

As aforementioned the force vs. time curves were directly obtained from the instrumented striker of the drop weigh tower. It has to be mentioned that the force time history curve has not been filtered according to the ASTM standard test D7136 [43]. Fig. 3 shows an example of these curves, one subcritical $(10 \mathrm{~J})$ in which no damage is induced, and the other supercritical $(50 \mathrm{~J})$ which produces damage. The first one shows a sinusoidal shape as it expected, since the behaviour of the plate is similar to a spring. For the supercritical test, images of the back face of the lam inate obtained by means of a high speed camera are shown for four different instants; these images allows to identify the initiation and development of the fibre failure. Point A corresponds to a point in which no fibre damage appear. The point B identifies the Mean Static Ultimate Force (MSUF) of the structure [32,35], where a sud den force drop is registered and the fibre failure can be observed. Fibre failure progresses reaching its maximum length in the point $\mathrm{C}$, which correspond to the maximum displacement of the lami nate, and finally it tends to close as it can be seen in the point D. The total contact time duration and the peak force for the CSIPAP are directly obtained from this curves.

\subsection{Peak force}

The peak force as a function of the impact energy for all the impactor masses and laminate thicknesses considered is shown in Fig. 4. It could be observed that for the thinner laminates the peak force slightly increases with the impact energy. For thicker laminates, two different slopes are observed; from an impact energy of around $20 \mathrm{~J}$ onwards, the peak force increases in a similar manner as it does in the thinner laminates, whereas below $20 \mathrm{~J}$ the peak force is sensible smaller. This change in the slope is due to the fact that no delamination or fibre failure was induced at $10 \mathrm{~J}$ in the thicker laminates (confirmed with C Scan) while at $20 \mathrm{~J}$ both delamination and fibre failure have already appeared causing the peak force to have a soft growing trend, almost constant, as shown in the work of Feraboli et al. [35] and Zabala et al. [32]. For the thinner laminates no slope change is observed, since for the mini mum energy considered $(10 \mathrm{~J})$, delamination and fibre failure is already induced. It is possible to state that no influence on the impactor mass is found for the two studied laminates attending to the peak force. 


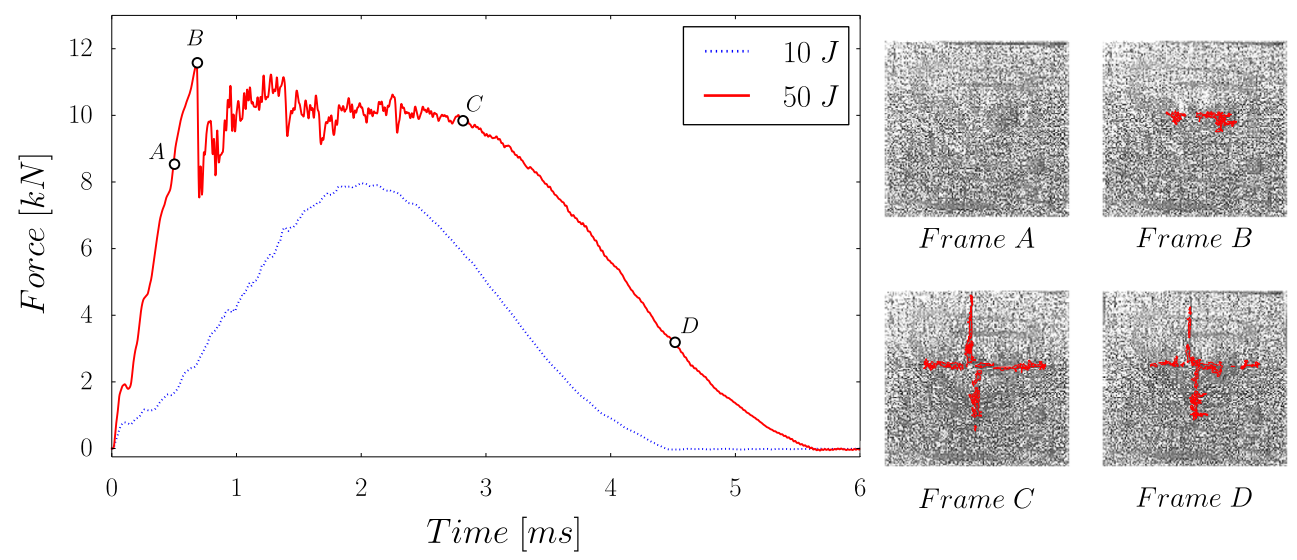

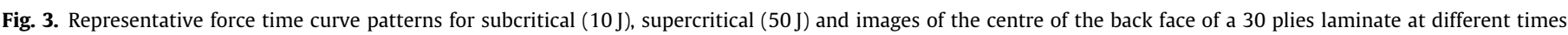
impacted at $50 \mathrm{~J}$.

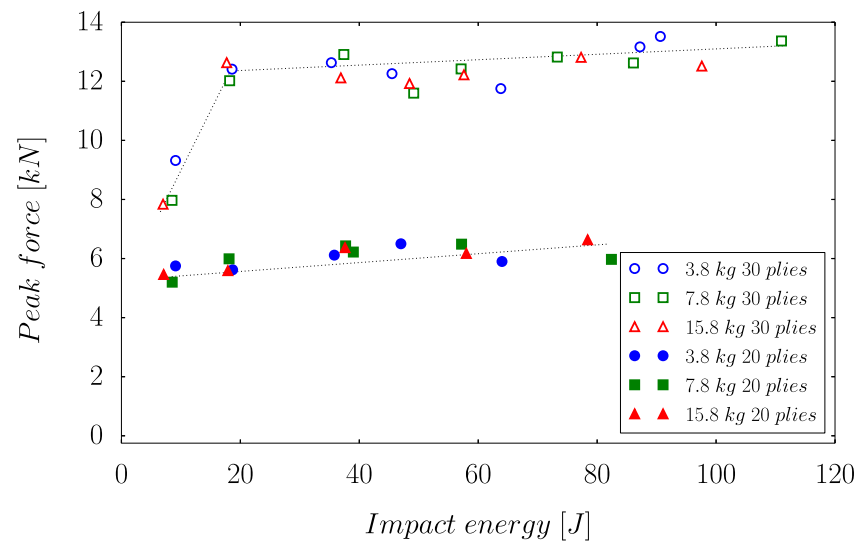

Fig. 4. Peak force as a function of impact energy for both laminate thicknesses.

\subsection{Energy and $\mathrm{COR}$}

In order to study the response of the laminates in terms of energy, the COR [35] is depicted for all the cases considered in Fig. 5. The COR is defined as:

$\operatorname{COR} \sqrt{\frac{E_{i} \quad E_{D}}{E_{i}}}$

where $E_{i}$ is the impact energy and $E_{D}$ is the laminate dissipated energy. Given that the range of impact energies studied in this work is relatively high (until full perforation), the non conservative energy is neglected when compared to the energy dissipated by the laminate in terms of damage [44]. It is observed that the COR value diminishes for both laminates as the impact energy increases due to the higher dissipated energy through different failure mech anism. The COR value in the thicker laminates begins close to one because the laminates impacted at that energy do not present fail ure. The thinner laminates present delamination and fibre failure for all the energy range studied. Above $80 \mathrm{~J}$, thinner laminates pre sents a sudden slope change in the COR value, which it is related to cases where the impactor nearly penetrates the laminate; in case of penetration at the ballistic limit velocity (the minimum velocity for full penetration) the COR would be zero. Both figures for the two thicknesses studied show no impactor mass influence, since it is not possible to observe any clear tendency for a given mass. Being the dissipated energy directly related to the quantity of damage induced in the laminate, it is expected that the impactor mass would not sensibly affect the laminate damage; this will be clarify in the damage analysis section.

\subsection{Total time of contact}

Fig. 6 shows the total time of contact between the impactor and the laminate as a function of the impact energy for the different impactor masses and laminate thicknesses considered. It is observed that as the impact energy increases, the contact time also increases; this happens because the damage in the laminate becomes larger, making the specimen more compliant. Regarding the thickness of the laminates, the total contact duration for the

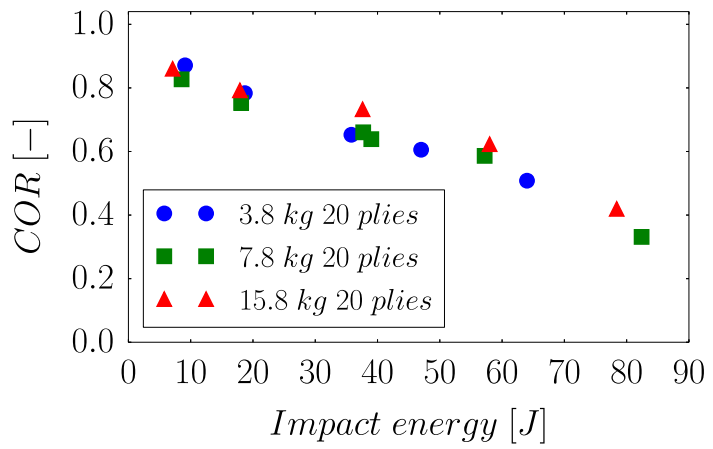

(a) 20 plies laminate

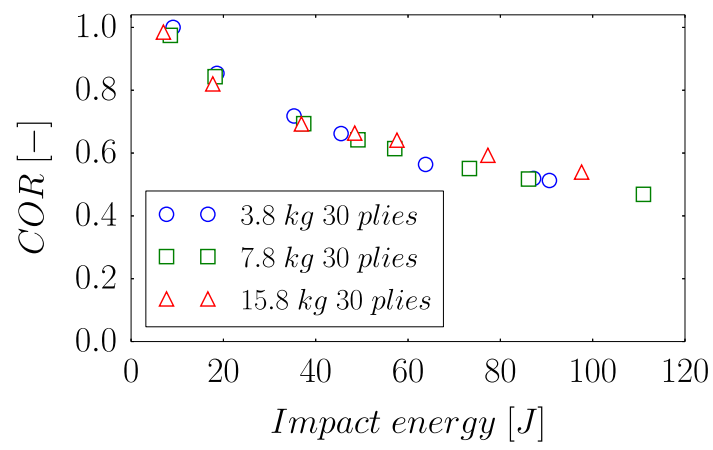

(b) 30 plies laminate

Fig. 5. COR evolution vs. impact energy for both laminate thicknesses 


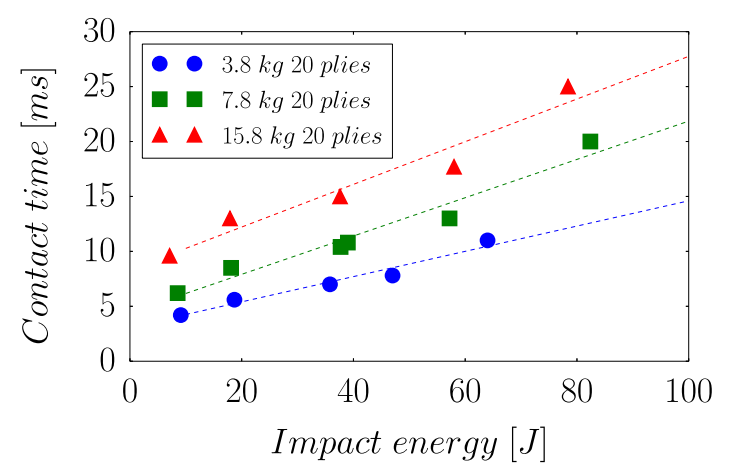

(a) 20 plies laminate

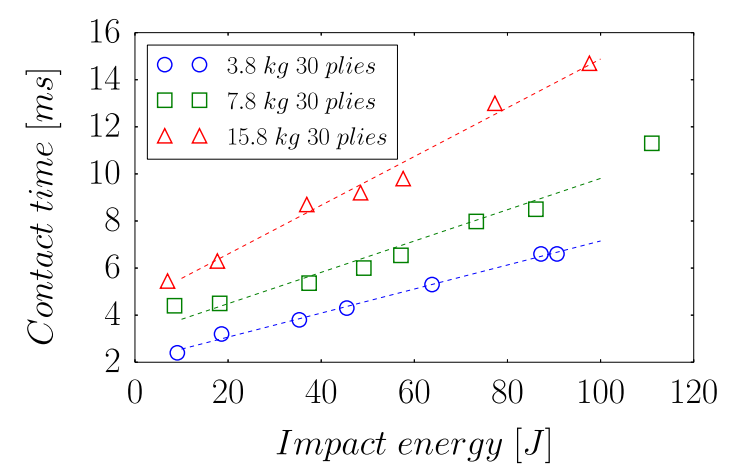

(b) 30 plies laminate

Fig. 6. Contact time vs. impact energy for both laminate thicknesses.

thicker laminates is around 2 times smaller than for the thin lam inates due to the higher stiffness of the first ones.

It can also be observed a clear influence of impactor mass in such a way that for a given impact energy the heavier impactor, and therefore slower, remains a longer time in contact with the laminate. The differences are similar to the differences in the initial impact velocity, which could indicate that this parameter have scaled in time the overall process of impact. Nevertheless, to have a better understanding of the phenomenon, the final displacement among the different masses impacted is plotted, Fig. 7. The results confirm the previous explanation, since no influence of impactor mass can be observed. It has to be mentioned also that, as

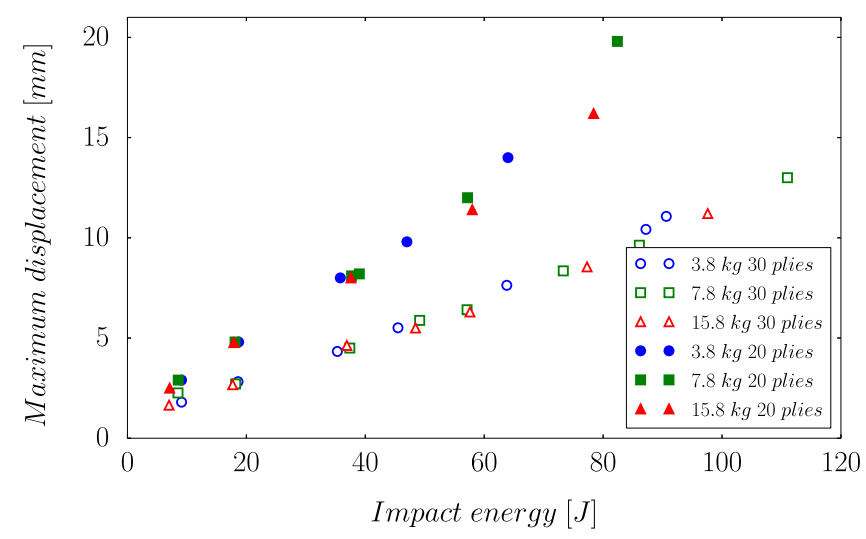

Fig. 7. Maximum displacement as a function of the impact energy for different impactor mass and two laminate thicknesses. expected, the final displacement is smaller for the thicker laminates.

\subsection{Residual transverse stiffness}

The CSIPAP presents a methodology to measure the residual transverse stiffness of laminates by means of a three test proce dure: a subcritical impact (in which no damage is induced) on an intact specimen, the nominal impact test at a given energy, and a second subcritical impact on a damaged specimen [45]. In the elas tic regime, contact duration between the striker and the specimen is independent of the impact energy and only depends on the effec tive structural system $t_{c} \quad \pi \sqrt{ } m / K_{0}$ where $t_{c}$ is the contact time, $m$ is the impactor mass, and $K_{0}$ is the effective transverse stiffness of the intact specimen. Due to this, the normalised residual trans verse stiffness $\bar{K}_{D 0}$ can be obtained using the following relation $\bar{K}_{D 0} \quad K_{D} / K_{0} \quad\left(t_{0} / t_{D}\right)^{2}$, where $K_{D}$ is the effective transverse stiff ness of the damaged specimen, and $t_{D}$ and $t_{0}$ are the time of con tact of a subcritical impact on a damaged and an undamaged specimen.

Fig. 8 shows the normalised residual transverse stiffness for both analysed thicknesses, as function of the impact energy. It could be observed that it diminishes as the impact energy increases due to the rising of the damage induced in the laminate. As happened in the COR plots, the normalised residual transverse stiffness curves do not show a clear trend regarding the influence of the impactor mass for this particular range of impact energies. Finally, as expected, the normalised residual transverse stiffness for the thicker laminates is slightly bigger than for the thinner laminates.

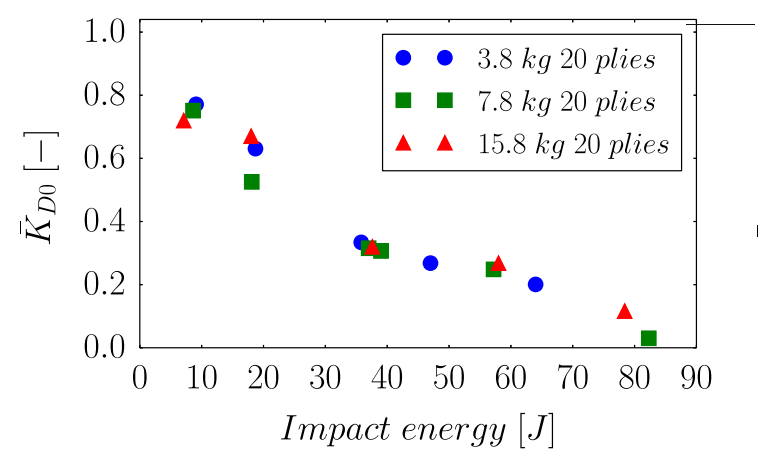

(a) 20 plies laminate

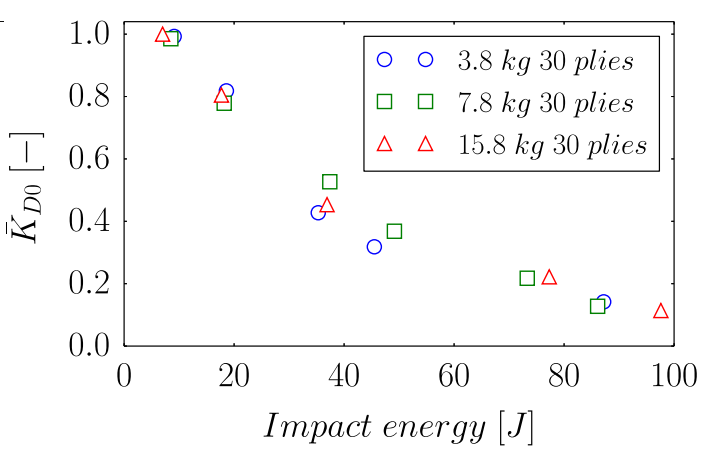

(b) 30 plies laminate

Fig. 8. Normalised residual transverse stiffness vs. impact energy for 20 and 30 plies laminate thicknesses. 


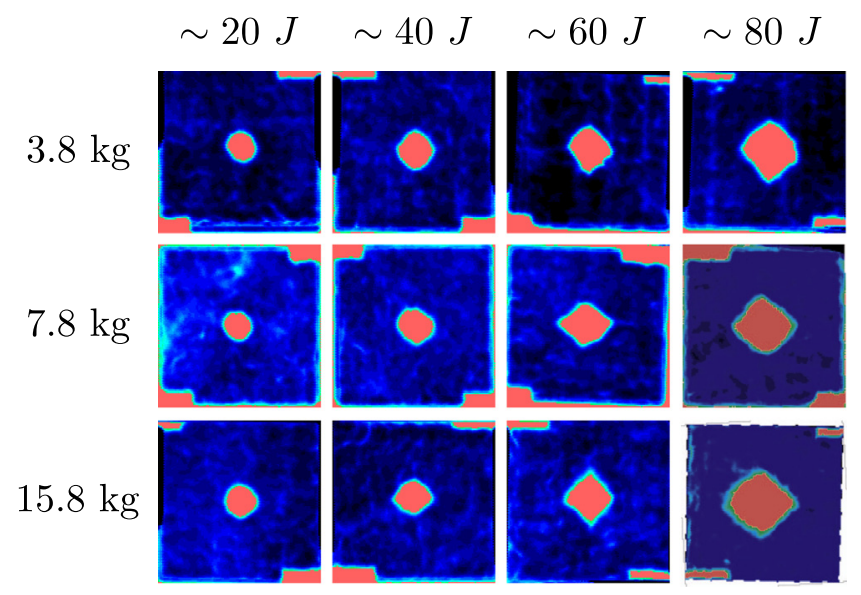

Fig. 9. Comparison of the C-Scan results for a 30 plies laminate, impacted at different energies with different impactor masses.

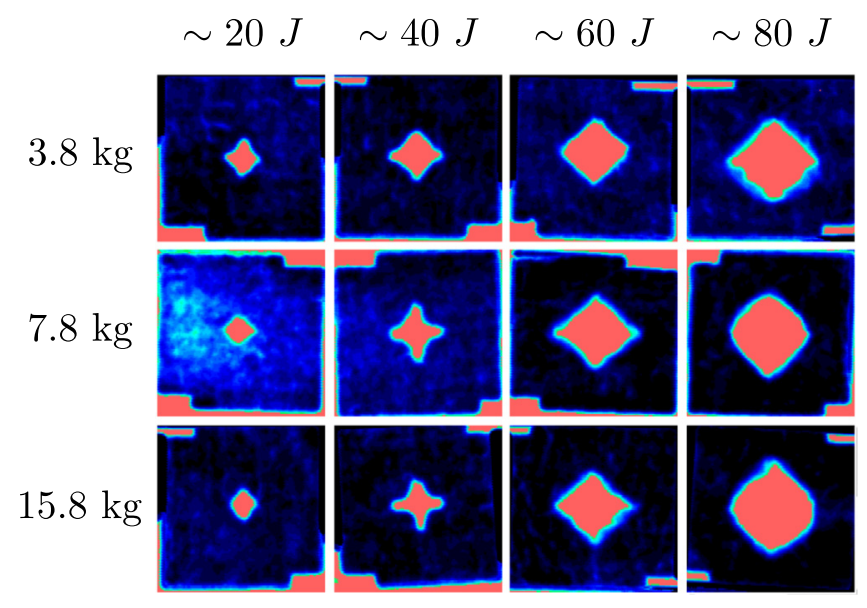

Fig. 10. Comparison of the C-Scan results for a 20 plies laminate impacted at different energies with different impactor masses.

\section{Damage analysis}

\subsection{Conventional C Scan}

The analysis of the experimental tests using the CSIPAP methodology, has not revealed any impactor mass influence in any of the variables analysed: peak force, contact duration, COR and normalised residual transverse stiffness. With the results pre sented, it is possible to state that the amount of energy dissipated by the laminate in terms of damage it is not influenced by the impactor mass for equienergetic impacts. In this section a detailed non destructive analysis is performed in order to evaluate if this dissipated energy is associated to the same damage mechanisms, or the relative importance of each one depends on the impactor mass.

The conventional C Scan procedure was used to obtain the shape and extension of the delamination. The C Scan inspections for the 30 plies laminates are presented in Fig. 9. The images show the projected damage areas of the laminates impacted from 20 to $80 \mathrm{~J}$ for the three impactor masses studied; the laminates impacted at $10 \mathrm{~J}$ are not included since no damage was found. The shape of the damaged area is circular for the impacts performed at $20 \mathrm{~J}$, and as the impact energy increases it tends to a diamond pattern. This evolution is the same for the three impactor mass analysed.

Fig. 10 shows the $C$ Scan for the 20 plies laminates. In this case the shape of the projected delaminated area is a diamond (or cru ciform) from the lowest impact energy. As for the thicker lami nates, both the shape and the size are very similar no matter of the impactor mass used.

As a summary of the damaged areas, Fig. 11 shows a graph with the delaminated area vs. the impact energy for all impact cases with damage. As the impact energy increases the extension of the damage grows, independently of the mass or impactor velocity. The conventional C Scan has hence not revealed any influence of impactor mass neither in the shape or in the extension. In contrast, the experimental study performed by Zabala et al. [32] for woven carbon epoxy laminates shows that the delaminated area increases with the impactor mass for equienergetic impacts. This difference could be related to the different impact energy range studied in that work (4 and $8 \mathrm{~J}$ ), in which the dominant failure mechanism is delamination, which is strain rate sensitive since is dominated by the epoxy matrix mechanical properties $[33,46]$.

\subsection{Phased array ultrasonic inspections}

An Olympus Omniscan SX phased array ultrasonic system is used to analyse the location of the delaminations through the thickness of the laminate. Fig. 12 shows the in depth C Scan of the thicker laminate impacted at $20 \mathrm{~J}$ for the different impactor masses. The colour (please referred to the online version of the paper) indicates the depth of the first delamination found by the scan. It can be seen how the delamination area increases with the depth, producing a frustum cone shaped delamination, that it is better depicted in Fig. 13 where the B scan is presented for the same laminate thickness for an impact of $40 \mathrm{~J}$. This is a very well known effect, firstly reported by Cantwell et al. [2].

Analysing Figs. 12 and 13, it is possible to conclude that no influence of impactor mass is found. A very similar result is

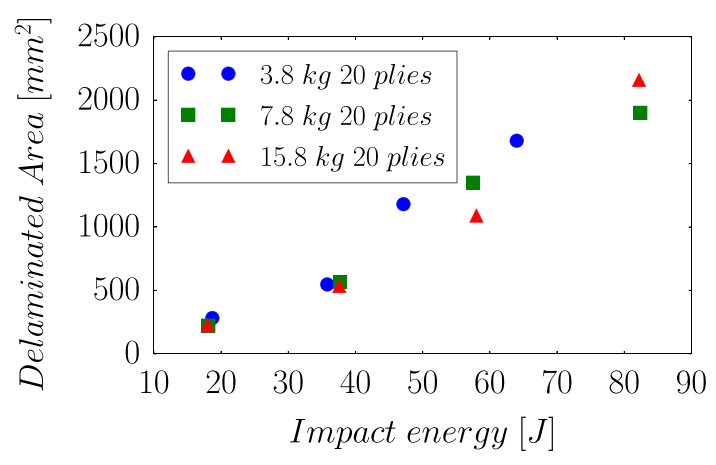

(a) 20 plies laminate

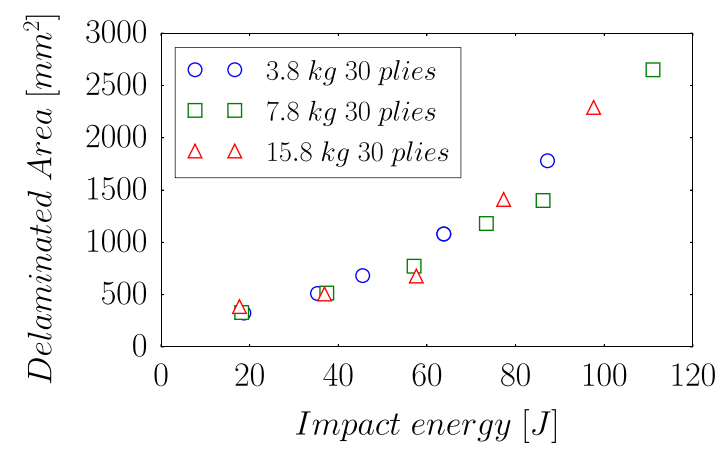

(b) 30 plies laminate

Fig. 11. Delaminated area vs. impact energy for both laminates thicknesses. 


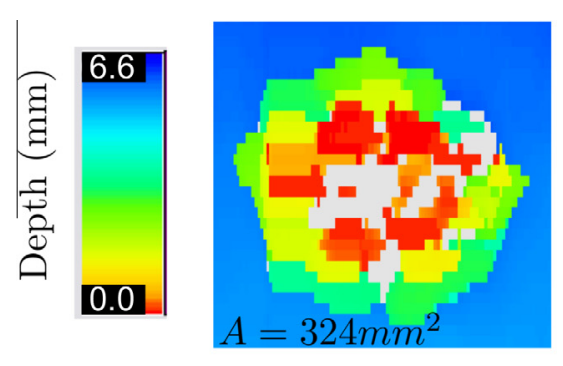

$3.8 \mathrm{~kg}$

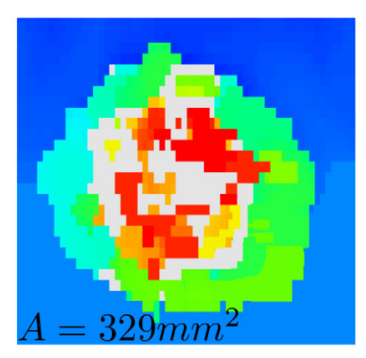

$7.8 \mathrm{~kg}$

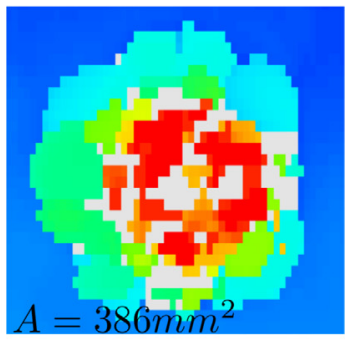

$15.8 \mathrm{~kg}$

Fig. 12. Detailed C-Scan for the laminate of 30 plies impacted at $20 \mathrm{~J}$ for the three different impactor masses.
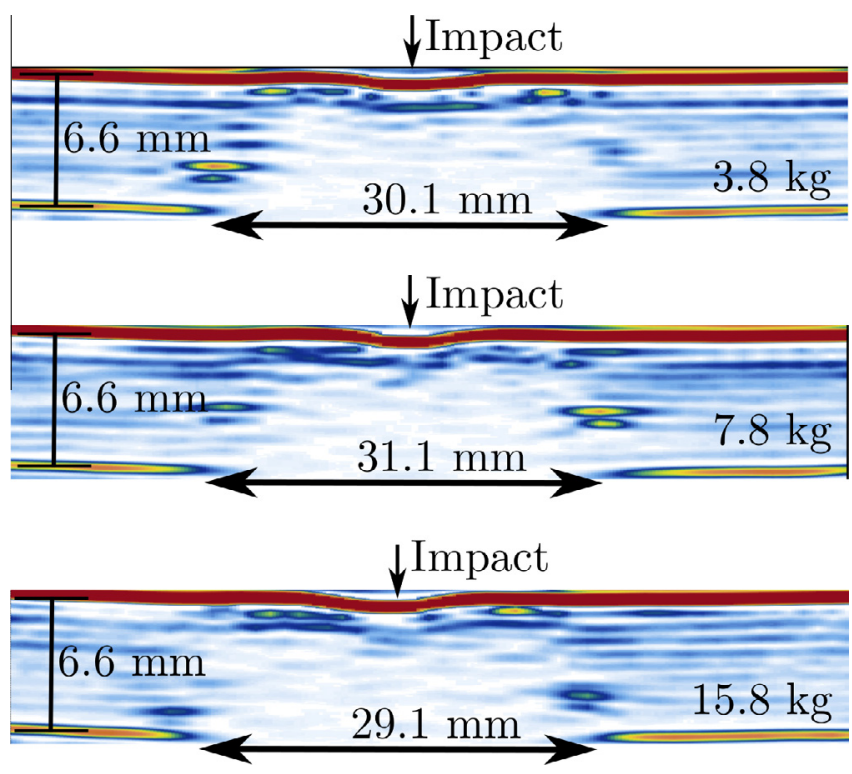

Fig. 13. Phased array B-Scan performed for impacts at $40 \mathrm{~J}$ for the laminate of 30 plies with the three different impactor masses.

obtained for the 20 plies laminates. It can be concluded, after the damage analysis, that the delaminated area, the in plane delami nated shape and the through thickness delaminated shape does not show impactor mass influence for equienergetic impacts, rein forcing the idea that in this range of energy, mass influence on the behaviour of carbon/epoxy woven laminates is negligible.

\section{Conclusions}

Low velocity impact test have been performed with different impactor masses in order to analyse its influence on the induced impact damage. Thanks to the CSIPAP methodology, it can be said that no influence of this parameter has been observed in the beha viour of composites laminates at this energy range where fibre damage and delamination occurred. Peak force, COR, maximum displacement and residual stiffness plots are function of impact energy alone and not velocity impact or impactor mass separately. Total contact duration shows a difference trends for each impactor mass. This is not caused by a different behaviour of the impacted laminated, but it is explained due to the different initial velocity in equienergetic impacts. As it is expected, differences regarding laminate thickness has been observed in the previous parameters, resulting for the thicker one in higher peak force, higher COR, lower contact duration, lower final displacement and higher residual stiffness at the same impact energy.

The damage inspection performed, using two different tech niques (conventional C Scan and phased array) allows to obtain the in plane and through thickness delamination shape. It has been also observed that impactor mass has no influence in the damaged generated, neither the extension nor the topology. This results con firms the conclusions obtained using the CSIPAP methodology, spe cially the COR and residual stiffness results, both of them directly related with the damage generated.

Some authors [32] have observed impactor mass influence (in equienergetic impacts) in the damage generated in woven car bon/epoxy laminates at an energy range in which interlaminar damage is dominant, which is attributed to the strain rate sensitiv ity in interlaminar fracture toughness. When intralaminar damage (particularly fibre failure) appears, no influence of impactor mass has been found, even if tensile strength, which is the mechanical property that governs the fibre failure is rate sensitive in woven laminates [37]. In order to explain these differences let's analyse the value of the strain rate in this type of impacts. The strain rate $\dot{\varepsilon}$ could be estimated as $\dot{\varepsilon} \quad v / L$, where $v$ is the impact velocity and $L$ the characteristic length. For the interlaminar fracture tough ness the strain rate characteristic length is the thickness, whereas for the fibre tensile strength is the span of the laminate. This fact means that the strain rate associated to the fibre failure is at least one order of magnitude lower than the one associated to the frac ture toughness. In this work for a $40 \mathrm{~J}$ impact test, the strain rate associated to tensile strength varies from $\sim 30 \mathrm{~s}^{1}$ (for the heaviest mass) to $\sim 60 \mathrm{~s}^{1}$ (for the lightest mass). This variation has negligi ble influence in the strength properties as Foroutan et al. [37] shows. They analysed experimentally the strain rate sensitivity of carbon/epoxy woven laminates under tension, showing a variation of $10 \%$ in the tensile strength properties between an static test and a dynamic test at $320 \mathrm{~s}^{1}$.

\section{Acknowledgement}

This research was done with the financial support of the Spanish Ministry of Economy and Competitiveness under Project reference DPI2013 41094 R.

\section{References}

[1] Cantwell W, Morton J. Comparison of the low and high velocity impact response of cfrp. Composites 1989;20:545-51.

[2] Cantwell W, Morton J. Impact perforation of carbon fibre reinforced plastic. Compos Sci Technol 1990;38:119-41.

[3] Cantwell W. The influence of target geometry on the high-velocity impact response of cfrp. Compos Struct 1988;10:247-65.

[4] Cantwell W. The influence of fiber stacking-sequence on the high-velocity impact response of cfrp. J Mater Sci Lett 1988;7:756-8.

[5] Chen J, Allahdadi F, Carney T. High-velocity impact of graphite/epoxy composite laminates. Compos Sci Technol 1997;57:1369-79.

[6] Pernas-Sánchez J, Artero-Guerrero JA, Varas D, López-Puente J. Experimental analysis of normal and oblique high velocity impacts on carbon/epoxy tape laminates. Compos Part A 2014;60:24-31.

[7] López-Puente J, Zaera R, Navarro C. The effect of low temperatures on the intermediate and high velocity impact response of cfrps. Compos Part B 2002;33:559-66. 
[8] López-Puente J, Zaera R, Navarro C. Experimental and numerical analysis of normal and oblique ballistic impacts on thin carbon/epoxy woven laminates. Compos Part A 2008;39:374-87.

[9] Pernas-Sánchez J, Artero-Guerrero JA, Zahr-Viñuela J, Varas D, López-Puente J Numerical analysis of high velocity impacts on unidirectional laminates. Compos Struct 2014;107:629-34.

[10] Varas D, Artero-Guerrero JA, Pernas-Sánchez J, López-Puente J. Analysis of high velocity impacts of steel cylinders on thin carbon/epoxy woven laminates. Compos Struct 2013;95:623-9.

[11] Sun C, Potti V. A simple model to predict residual velocities of thick composite laminates subjected to high velocity impact. Int J Impact Eng 1996;18:339-53.

[12] López-Puente J, Zaera R, Navarro C. An analytical model for high velocity impacts on thin cfrps woven laminates. Int J Solids Struct 2007;44:2837-51.

[13] Caprino G, Visconti IC, Ilio AD. Composite materials response under lowvelocity impact. Compos Struct 1984;2:261-71.

[14] Cantwell W, Curtis P, Morton J. An assessment of the impact performance of cfrp reinforced with high-strain carbon fibres. Compos Sci Technol 1986;25:133-48.

[15] Dransfield K, Baillie C, Mai Y. Improving the delamination resistance of cfrp by stitching-a review. Compos Sci Technol 1994;50:305-17.

[16] Soutis C, Curtis P. Prediction of the post-impact compressive strength of cfrp laminated composites. Compos Sci Technol 1996;56:677-84.

[17] Sala G. Post-impact behaviour of aerospace composites for high-temperature applications: experiments and simulations. Compos Part B 1997;28:651-65.

[18] Larsson F. Damage tolerance of a stitched carbon/epoxy laminate. Compos Part A 1997;28:923-34.

[19] Reis L, de Freitas M. Damage growth analysis of low velocity impacted composite panels. Compos Struct 1997;38:509-15.

[20] Pavier M, Clarke M. Experimental techniques for the investigation of the effects of impact damage on carbon-fibre composites. Compos Sci Technol 1995;55:545-51.

[21] Jackson W, Poe C. The use of impact force as a scale parameter for the impact response of composite laminates. J Compos Technol Res 1993;15:282-9.

[22] Kim J, Leung L, Lee W, Hirai Y. Impact performance of a woven fabric cfrp laminate. Polym Polym Compos 1996;4:549-61.

[23] Johnson A, Pickett A, Rozyckic P. Computational methods for predicting impact damage in composite structures. Compos Sci Technol 2001;61:2183-92.

[24] Hou J, Petrinic N, Ruiz C, Hallett S. Prediction of impact damage in composite plates. Compos Sci Technol 1997;60:273-81.

[25] de Moura M, Marques A. Prediction of low velocity impact damage in carbonepoxy laminates. Compos Part A 2002;33:361-8.

[26] Li C, Hu N, Yin Y, Sekine H, Fukunaga H. Low-velocity impact-induced damage of continuous fiber-reinforced composite laminates. Part I: an fem numerical model. Compos Part A 2002;33:1055-62.

[27] de Moura M, Gonçalves J. Modelling the interaction between matrix cracking and delamination in carbon-epoxy laminates under low velocity impact. Compos Sci Technol 2004;64:1021-7.

[28] Chen L, Zhang W, Li H, Yang J. Numerical approach to damages in a composite laminated plate under a low-velocity impact. Int J Nonlinear Sci Numer 2007;8:581-7.
[29] Lopes C, Camanho P, Gürdal Z, Maimí P, González E. Low-velocity impact damage on dispersed stacking sequence laminates. Part II: Numerical simulations. Compos Sci Technol 2009;69:937-47.

[30] Zhou G, Lloyd J, McGuirk J. Experimental evaluation of geometric factors affecting damage mechanisms in carbon/epoxy plates. Compos Part A 2001;32:2279-86.

[31] Nettles AT, Douglas MJ. A comparison of quasi-static indentation to lowvelocity impact. NASA Technical Report; 2000.

[32] Zabala H, Aretxabaleta L, Castillo G, Urien J, Aurrekoetxea J. Impact velocity effect on the delamination of woven carbon-epoxy plates subjected to lowvelocity equienergetic impact loads. Compos Sci Technol 2014;94:48-53.

[33] López-Puente J, Li S. Analysis of strain rate sensitivity of carbon/epoxy woven composites. Int J Impact Eng 2012;48:54-64.

[34] Ambur DR, Kemmerly HL. Influence of impactor mass on the damage characteristics and failure strength of laminated composites plates, 39th AIAA/ASME/ASCE/AHS/ASC structures. Struct Dyn Mater Conf 1998:98-1784.

[35] Feraboli P, Kedward KT. A new composite structure impact performance assessment program. Compos Sci Technol 2006;66:1336-47.

[36] Bucinell R, Nuismer RJ, Koury JL. Response of composites plates to quasi-static impact events. ASTM STP 1991;1110:528-49.

[37] Foroutanb R, Nemesa J, Ghiasib H, Hubertb P. Experimental investigation of high strain-rate behaviour of fabric composites. Compos Struct 2013;106:261-71.

[38] Fitoussi J, Meraghni F, Jendli Z, Hug G, Baptiste D. Experimental methodology for high strain-rates tensile behaviour analysis of polymer matrix composites. Compos Sci Technol 2005;65:2174-88.

[39] Hosur M, Adya M, Vaidya U, Mayer A, Jeelani S. Effect of stitching and weave architecture on the high strain rate compression response of affordable woven carbon/epoxy composites. Compos Struct 2003;59:507-23.

[40] Hosur M, Islam SW, Vaidya U, Kumar A, Dutta P, Jeelani S. Dynamic punch shear characterization of plain weave graphite/epoxy composites at room and elevated temperatures. Compos Struct 2005;70:295-307.

[41] Robinson P, Davies G. Impactor mass and specimen geometry effects in low velocity impact of laminated composites. Int J Impact Eng 1992;12:189-207.

[42] Zabala H, Aretxabaleta L, Castillo G, Aurrekoetxea J. Loading rate dependency on mode I interlaminar fracture toughness of unidirectional and woven carbon fibre epoxy composites. Compos Struct 2015;121:75-82.

[43] American Society for Testing Materials. Standard test method for measuring the damage resistance of a fibre-reinforced polymer matrix composite to a drop-weight impact event. ASTM-D7136 2007.

[44] Caprino G, Lopresto V, Langella A, Durante M. Irreversibly absorbed energy and damage in \{GFRP laminates impacted at low velocity. Compos Struct 2011;93:2853-60.

[45] Feraboli P, Kedward K. Enhanced evaluation of the low-velocity impact response of composite plates. AIAA J 2004;42:2143-52.

[46] Gilat A, Goldberg R, Roberts G. Strain rate sensitivity of epoxy resin in tensile and shear loading. J Aerosp Eng 2007;20:75-89. 